\title{
Monitoring and Assessing Urban Heat Island Variations and Effects in the United States
}

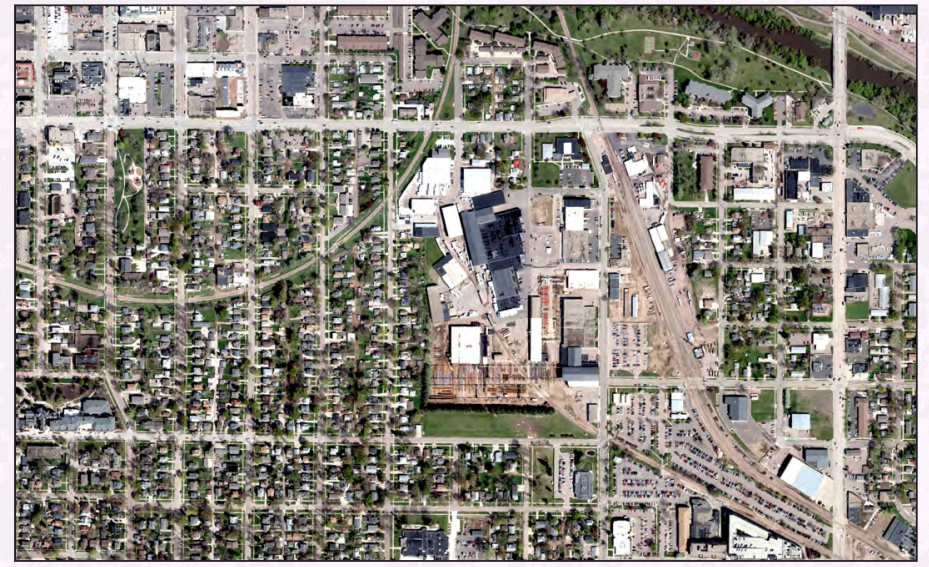

High resolution image of Sioux Falls, 2017.

\section{Background}

Urban heat islands (UHIs) are urbanized areas that experience higher temperatures than surrounding nonurban areas. Structures such as buildings, roads, and other infrastructure absorb and reemit the heat from the Sun more than natural landscapes such as forests and water bodies. The intensity of UHIs varies with population size, urban extent, and local background climate (Manoli and others, 2019). UHI has a profound effect on the lives of urban residents and can exacerbate the risk of heat-related mortality associated with global climate change (U.S. Environmental Protection Agency [EPA], 2021b). Among the many damaging weather-related extremes, heat waves have the potential to cause a substantial effect on human health, energy demand, and human and ecosystem health challenges (Zhao and others, 2018). As the climate of the Earth warms, hotter-than-usual days and nights are becoming more common, and heat waves are expected to become more frequent and intense. The UHI effect is expected to strengthen in the future as the structural and spatial extent and population density of urban areas change and grow. Measures of UHI intensity complement trends in urban temperature as indicators to examine the effects of changing climate conditions over time (EPA, 2021a; U.S. Global Change Research Program [USGCRP], 2021).

Land surface temperature is a fundamental measurement for describing climate effects on ecosystem functioning. Changes in land surface temperature can disrupt a wide range of natural processes, particularly if these changes occur more quickly than plant and animal species can adapt. Temperature changes over urban areas provide important evidences for the effects of increasing anthropogenic activities and thermal stress with changes in climate condition. The U.S. Geological Survey (USGS) has continuously acquired images of the Earth's land surface through the Landsat series of Earth observation satellites, providing uninterrupted data to help natural resources management and research. Landsat surface temperature that detects and monitors thermal condition change of the Earth's surface is an important geophysical parameter in global energy balance studies and is useful for monitoring UHI (Xian and others, 2021).

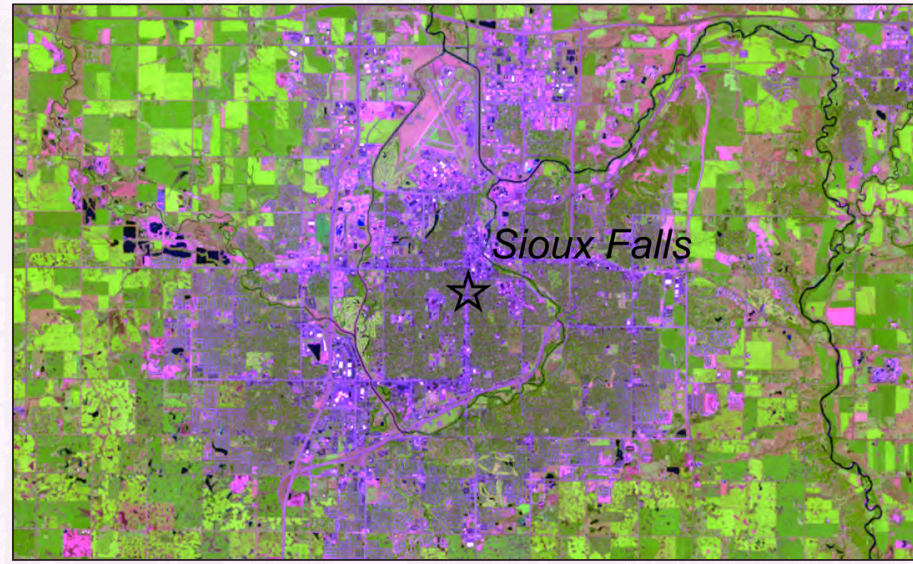

Landsat image of Sioux Falls with a band combination of b6, 4, 3 .

\section{Study Applications}

The USGS and EPA interagency effort focuses on integrating longterm Landsat surface temperature data and annual land cover change information from the 1980s to the present (2021) to monitor and assess UHI effects in the United States. The integration of surface temperature and land cover dynamics provides fundamental measurements for UHI intensity and temporal trends in any urban location. The UHI change analysis also identifies thermal characteristics in the urban-wildland interface and UHI hotspots that are vulnerable to intense heat waves. Annual UHI patterns and trends can be created as indicators of the effect of climate variation on a wide range of ecosystems processes, particularly if these extreme warming events occur frequently and more quickly than society and ecosystems can adapt. The data and products developed from this effort can be used to determine the capability to monitor and assess UHI and UHI change effects for the Nation. In addition to the USGS and EPA, National Oceanic and Atmospheric Administration scientists have expressed interest in the data and products for research related to the evaluation of enhanced urban temperature patterns and the effect of urban sprawl on climatological observations (for example, Gallo and Xian, 2016).

\section{Urban Heat Island Intensity}

A data processing and analysis system has been developed at the USGS Earth Resources Observation and Science (EROS) Center. The system processes all Landsat land surface temperature records to generate annual means and trends. The analysis quantifies urban and surrounding nonurban land cover types and their extents. UHI intensity is then quantified by differing surface temperature between urban and surrounding nonurban areas. High intensity urban land cover usually causes high surface temperature (fig. 1). By comparing surface temperatures in urban and nonurban areas within a 5-kilometer buffer zone, UHI intensities and their temporal trends were calculated between 1985 and the 2010s in the five prototype cities: Atlanta, Georgia; Houston, Texas; Minneapolis, Minnesota; Sioux Falls, South Dakota; and Phoenix, Arizona (fig. 2). Generally, UHI intensities 
indicate positive magnitudes for most urban pixels. Temporal variations of UHI intensity indicate positive trends in four cities with magnitudes of $0.2-0.6$ degree per decade but a slightly negative trend in Phoenix.

The positive trends of UHI intensity are more apparent in warm and wet climate regions than in dry regions. The prototype approach can be implemented to assess UHI in other major cities in the United States.

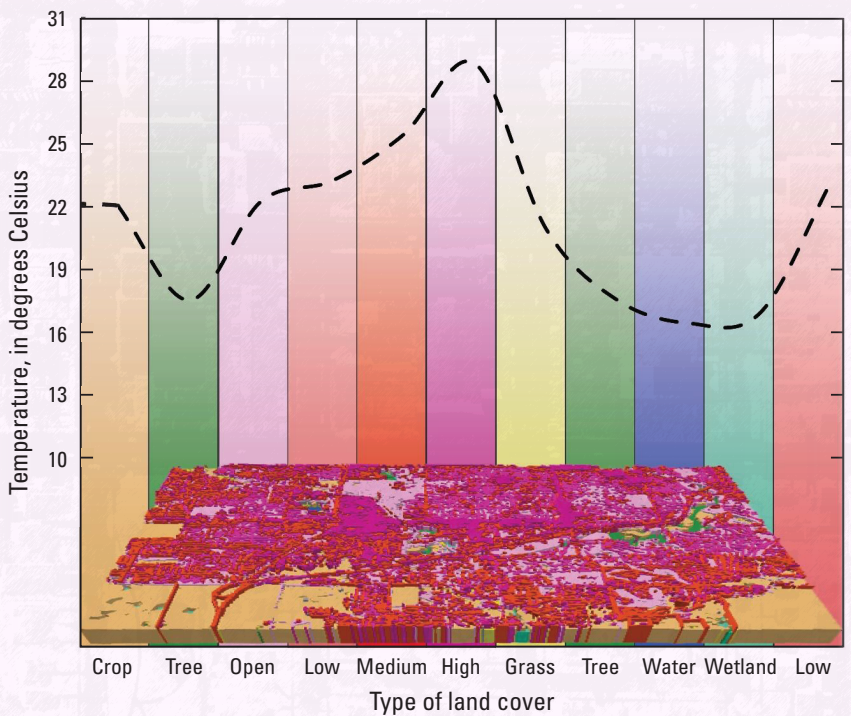

Figure 1. Land surface temperature (LST), in degrees Celsius (y-axis), for different types of land cover (x-axis). Four urban land cover categories, shown as high intensity (high), medium intensity (medium), low intensity (low), and open land development (open), are compared with other nonurban land covers. The LST is larger in urban areas than in nonurban areas. The high intensity urban land cover has the largest LST. The annual mean LST and the land cover are for 2017 in downtown Sioux Falls, South Dakota.
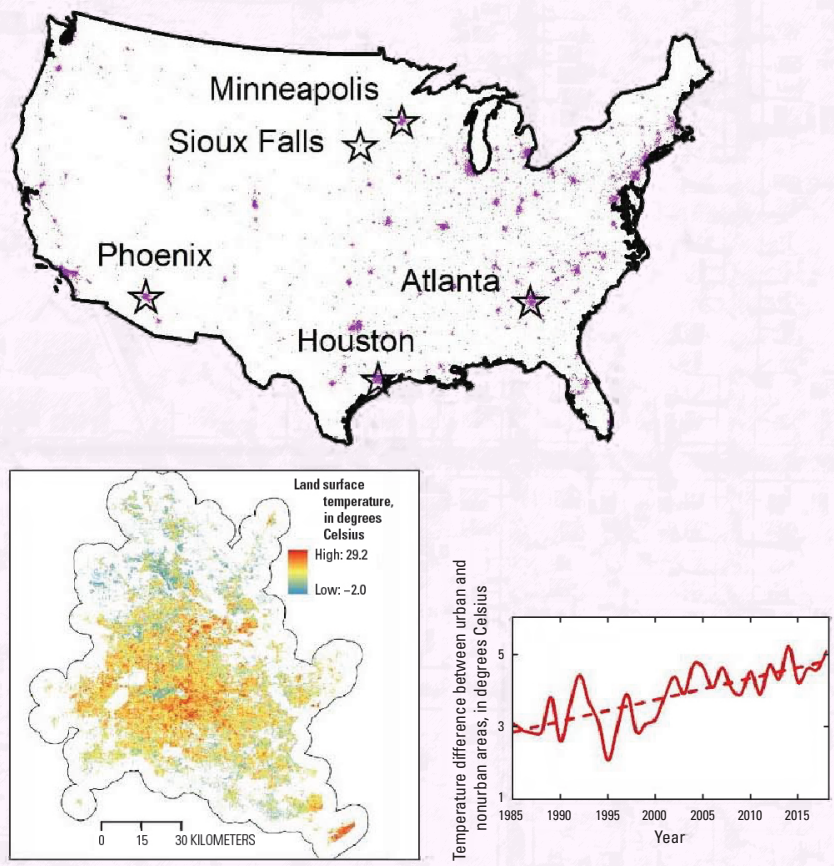

Figure 2. Urban extent in the conterminous United States. The UHI intensity, shown as LST differences between urban and nonurban areas (2016) and mean annual UHI intensity (solid line) (1985-2018) in the metropolitan center of Houston, show the UHI intensity distribution and the change in the region. The linear regression for the mean annual UHI intensity (dashed line) indicates a positive trend in 1985-2018. Land surface temperature and UHI intensity data (1985-2018) are currently produced by the USGS EROS Center and are available for Atlanta, Houston, Minneapolis, Sioux Falls, and Phoenix.

\section{Products}

The primary product from this effort is a documented and operational dataset including geographic information system layers and trend analyses documenting changing conditions in urban areas such as the temporal trends in UHI intensity and distribution (currently 1985-2018), available as a USGS data release (Xian and Shi, 2021). The product meets the needs of a broad range of stakeholders. The initial UHI products were produced through the EROS Center. The datasets will continue to be made available for major U.S. cities for inclusion in the USGCRP and EPA climate indicators sets.

\section{References Cited}

Gallo, K., and Xian, G., 2016, Changes in satellite-derived impervious surface area at US historical climatology network stations: ISPRS Journal of Photogrammetry and Remote Sensing, v. 120, p. 77-83. [Also available at https://doi.org/10.1016/j.isprsjprs.2016.08.006.]

Manoli, G., Fatichi, S., Schläpfer, M., Yu, K., Crowther, T.W., Meili, N., Burlando, P., Katul, G.G., and Bou-Zeid, E., 2019, Magnitude of urban heat islands largely explained by climate and population: Nature, v. 573, p. 55-60. [Also available at https://doi.org/10.1038/s41586-019-1512-9.]

U.S. Environmental Protection Agency, [EPA], 2021a, Climate change indicators in the United States: U.S. Environmental Protection Agency web page, accessed April 15, 2021, at https://www.epa.gov/climate-indicators.

U.S. Environmental Protection Agency, [EPA], 2021b, Heat island effect: U.S. Environmental Protection Agency web page, accessed March 19, 2021, at https://www.epa.gov/heatislands.

U.S. Global Change Research Program [USGCRP], 2021, USGCRP indicator platform: U.S. Global Change Research Program web page, accessed March 19, 2021, at https://www.globalchange.gov/browse/indicators.

Xian, G.Z., and Shi, H., 2021, Land surface thermal feature change monitoring in urban and urban wild land interface (ver. 3.0, June 2021): U.S. Geological Survey data release, https://doi.org/10.5066/P9H6E1FZ.

Xian, G., Shi, H., Auch, R., Gallo, K., Zhou, Q., Wu, Z., and Kolian, M., 2021, The effects of urban land cover dynamics on urban heat island intensity and temporal trends: GIScience \& Remote Sensing, 15 p. [Also available at https://doi.org/10.1080/15481603.2021.1903282.]

Zhao, L., Oppenheimer, M., Zhu, Q., Baldwin, J.W., Ebi, K.L., Bou-Zeid, E., Guan, K., and Liu, X., 2018, Interactions between urban heat islands and heat waves: Environmental Research Letters, v. 13, 034003. [Also available at https://doi.org/10.1088/1748-9326/aa9f73.]

\section{By George Z. Xian}

For more information about this publication, contact: Director, USGS Earth Resources Observation and Science Center 47914 252nd Street

Sioux Falls, SD 57198

605-594-6151

Or

Michael Kolian

U.S. Environmental Protection Agency

Office of Atmospheric Programs

Washington, D.C.

kolian.michael@epa.gov

For additional information, visit: https://www.usgs.gov/centers/eros

Publishing support provided by the

ISSN 2327-6916 (print)

Rolla Publishing Service Center 